\title{
Neuroinflammation and fractalkine signaling in Alzheimer's disease
}

\author{
Dylan J. Finneran ${ }^{*}$ and Kevin R. Nash ${ }^{*}$ (D
}

\begin{abstract}
Alzheimer's disease (AD) is a progressive, neurodegenerative disorder, and the most common form of dementia. As the understanding of $A D$ has progressed, it is now believed that $A D$ is an amyloid-initiated tauopathy with neuroinflammation serving as the link between amyloid deposition, tau pathology, and neurodegeneration. As microglia are the main immune effectors in the central nervous system, they have been the focus of attention in studies investigating the neuroinflammatory component of AD. Therefore, recent work has focused on immunomodulators, which can alter microglial activation without suppressing activity, as potential therapeutics for $A D$. Fractalkine (CX3CL1; FKN), a unique chemokine with a one-to-one relationship with its receptor, signals through its cognate receptor (CX3CR1) to reduce expression of pro-inflammatory genes in activated microglia. Disrupting FKN signaling has opposing effects on the two hallmark pathologies of AD, but over-expressing a soluble FKN has been shown to reduce tau pathology while not altering amyloid pathology. Recently, differential signaling has been reported when comparing two cleavage variants of soluble FKN. These differential effects may explain recent studies reporting seemingly conflicting results regarding the effect of FKN over expression on AD pathologies.
\end{abstract}

Keywords: Neurodegeneration, Neuroinflammation, Fractalkine (CX3CL1), CX3CR1, Microglia

\section{Background}

In the central nervous system (CNS), fractalkine (CX3CL1; FKN)) is expressed predominantly on neurons, and its receptor (CX3CR1) is expressed solely on microglia [1]. Produced as a transmembrane protein with an $\mathrm{N}$-terminal chemokine domain followed by a long, mucin-like stalk, FKN can signal as either a membrane-bound protein or be cleaved by several proteases to generate a soluble fragment [2-4]. Signaling by FKN has been shown to reduce expression of pro-inflammatory genes in stimulated microglia $[5,6]$. Unlike other chemokines, fractalkine shares a one-to-one relationship with its receptor, allowing neurons to directly regulate microglial activity.

Research has shown a strong link between microglial activity and neurodegeneration in several neurodegenerative disorders. Given the ability of FKN to mediate microglial activation, it has been the subject of much interest. However, it appears as though the effects of FKN signaling is both context- and ligand-specific. For

\footnotetext{
* Correspondence: dfinnera@health.usf.edu; knash@health.usf.edu Department of Molecular Pharmacology and Physiology, Morsani College of Medicine, University of South Florida, 12901 Bruce B Downs Bvld, Tampa, FL
} 33612, USA

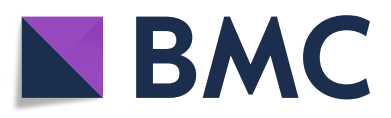

(c) The Author(s). 2019 Open Access This article is distributed under the terms of the Creative Commons Attribution 4.0 International License (http://creativecommons.org/licenses/by/4.0/), which permits unrestricted use, distribution, and reproduction in any medium, provided you give appropriate credit to the original author(s) and the source, provide a link to the Creative Commons license, and indicate if changes were made. The Creative Commons Public Domain Dedication waiver (http://creativecommons.org/publicdomain/zero/1.0/) applies to the data made available in this article, unless otherwise stated. instance, disrupting FKN signaling has been shown to be beneficial in stroke and models of amyloid deposition [7-10] while detrimental in tauopathy and Parkinson's disease (PD) models [11-13]. Reports from neuropathic pain and Alzheimer's disease (AD) models have further shown that there may be differential signaling elicited by full-length vs soluble FKN [14-16]. Here, we focus on the effects of FKN signaling in AD models as well as the differential effects of full length FKN signaling as compared to soluble FKN signaling.

\section{Alzheimer's disease \\ Alzheimer's disease, a fatal neurodegenerative disorder and the most common form of dementia, is character- ized by progressive cognitive decline and memory loss. Most AD cases are late-onset and sporadic with the greatest risk factor for acquiring $\mathrm{AD}$ being age. In adults greater than 85 , the prevalence of $\mathrm{AD}$ is greater than one in three, which results in a serious financial burden on patients and caregivers. Currently, there are no treat- ments that halt or slow the progression of the disease, and the pharmacotherapies available to patients only}


provide symptomatic relief that does not address the underlying pathology [17].

The two pathological hallmarks of AD are an accumulation of misfolded proteins: extracellular amyloid beta and intracellular microtubule-associated protein tau (MAPT). These inclusions lead to severe brain atrophy and neurodegeneration in the hippocampus and cortex. The current view is that $\mathrm{AD}$ is an amyloid-driven tauopathy [18]. Amyloid precursor protein (APP) is cleaved in a sequential manner first by $\beta$-secretase followed by $\gamma$-secretase, resulting in the generation of amyloid-beta $(\mathrm{A} \beta)$ and its subsequent accumulation. It is believed that this amyloid deposition triggers tau hyperphosphorylation and aggregation, which eventually leads to neurodegeneration. This is supported by the fact that individuals with Down syndrome, who have a triplication of all or part of chromosome 21 on which the amyloid precursor protein encoding gene resides, often develop amyloid plaques and an AD-like phenotype at a young age. Furthermore, all known mutations that cause familial AD either increase the production of or alter the aggregation properties of amyloid beta [19]. As such, many human trials have focused on clearing amyloid beta aggregates or reducing the amyloid burden on the human brain as a potential therapeutic [20]. A body of work has studied this approach, but it has yet to bear fruit.

\section{Neuroinflammation in Alzheimer's disease}

As research into $\mathrm{AD}$ has progressed, an addendum has been made to the amyloid cascade hypothesis which inserts neuroinflammation as the causal link between amyloid deposition, tau pathology, and neurodegeneration [18]. Support for this link comes from both human tissue and mouse models, in which activated microglia have been observed surrounding amyloid [21]. Using the microglial translocator protein (TSPO) ligand as a marker of microglial activation, longitudinal in vivo imaging of prodromal and $\mathrm{AD}$ cases have demonstrated that microglial activation correlates with amyloid burden [22]. Furthermore, there appears to be an initial increase in microglial activation early in the disease that is sustained, even if plaque burden decreases, suggesting chronic activation of microglia [23].

Epidemiological studies have found that long-term, high-dose non-steroidal anti-inflammatory use reduced an individual's risk for $\mathrm{AD}$ [24]. However, interventional as well as preventative trials have failed to show significant treatment effects $[25,26]$. The exact involvement of immune activation in $\mathrm{AD}$ pathogenesis, whether a cause or consequence, is still somewhat controversial. However, it has been shown that inflammation can drive AD pathogenesis once it has begun. Several studies have shown that increasing inflammation in models of amyloid deposition is beneficial while increasing inflammation in tauopathy models is detrimental [7, 27-29].

In an acute model, Lee et al. [29] stimulated microglia by injecting the endotoxin lipopolysaccharide (LPS) into the hippocampus of 4.5-month-old rTg4510 mice, a tauopathy model, and observed significant increases in pre-tangle phospho-tau 1 week after administration. In a chronic model of inflammation, hTau mice lacking the fractalkine receptor (CX3CR1) exhibited not only significantly greater pathology but also a significantly earlier onset of pathology and cognitive impairments. Furthermore, they observed in CX3CR1-deficient mice, systemic administration of LPS was sufficient to cause phosphorylation of endogenous tau at the paired helical filament-associated sites AT8 and AT180 [11]. These studies highlight the ability of pro-inflammatory activation of microglia to exacerbate, and even initiate, tau pathology.

Recently, genetic risk-factors for AD have been identified that are expressed uniquely in the innate immune system, implicating microglial involvement in $\mathrm{AD}$ susceptibility and/or pathogenesis [30-34]. Elevations in adaptive and innate immune markers have been widely reported in $\mathrm{AD}$-in both animal models and human subjects - and correlate with disease progression (reviewed in $[35,36])$. Polymorphism associations of IL-1 and TNF- $\alpha$ have been observed in $\mathrm{AD}$ patients $[37,38]$. Genome-wide association studies have identified more than 20 gene variants associated with an increased risk of late onset $\mathrm{AD}$ (LOAD), including CR1, CD33, MS4A, CLU, and HLA-DRB5 (reviewed in $[39,40]$ ). ApoE4 and, more recently, triggering receptor on myeloid cells (TREM) 2, were identified as conferring an increased risk of LOAD [41]. It has been proposed that overproduction of ApoE by activated glia might exacerbate inflammation, as ApoE4 stimulated IL-1 at significantly lower concentrations than ApoE3 [42]. The discovery of these innate immunity genes as risk factors for $\mathrm{AD}$ further strengthens the link between immune activation and $\mathrm{AD}$ pathogenesis.

The identification of immune-related gene risk factors for $\mathrm{AD}$ further implicates involvement of the immune system in disease etiology. It may be the case that immune activation and inflammation play a dual role in $\mathrm{AD}$, depending on the stage of the disease. Of the risk-associated genes discussed, all have been studied in the context of amyloid deposition and have shown that a reduction in phagocytic capacity is associated with increased amyloid burden. However, both TREM2 and CR1 have opposing effects on amyloid and tau pathology, in keeping with the body of work indicating that activation of microglia is beneficial for amyloid pathology while detrimental to tau pathology. However, 
microglial dysfunction may also play a role in disease progression.

There is evidence that microglial function is impaired in age and AD. Hickman et al. [43] observed reduced gene expression of amyloid beta-binding proteins, as well as reduced expression of amyloid-degrading enzymes. Furthermore, stimulation of a microglial cell line, with tumor necrosis factor (TNF) $\alpha$ recapitulated this phenotype, suggesting that sustained exposure to pro-inflammatory cytokines may inhibit microglial function. Recently, beclin 1 was implicated as a regulator of phagocytosis and was found to be impaired in human microglia isolated from late-stage $\mathrm{AD}$ cases [44]. Given the involvement of microglia in maintenance of CNS homeostasis and learning and memory, restoration of normal microglial function by modulating the inflammatory milieu may be a potential therapeutic target for AD [45].

The neuroinflammatory hypothesis, that links amyloid deposition to tau pathology via immune activation, has support from human tissue, mouse models, and genetic risk factors for $\mathrm{AD}$. It appears as though microglia become activated initially and may clear amyloid. However, as the disease progresses the ability of microglia to phagocytose amyloid reduces and this once protective immune activation turns neurotoxic, directly causing neurodegeneration and either leading to or exacerbating tau pathology. Since the failure of clinical trials using non-steroidal anti-inflammatory drugs to improve cognitive outcomes or reduce conversion to $\mathrm{AD}$, attention has turned to immunomodulators as potential therapeutics.
These compounds, such as CD200, CD22, and CX3CL1, modulate, rather than suppress, microglial activation.

\section{CX3CL1/CX3CR1}

Fractalkine is the only member of the $\mathrm{CX} 3 \mathrm{C}$ chemokine family and, unlike many other chemokines, shares a one-to-one relationship with its cognate receptor, CX3CR1 [46, 47]. CX3CR1 is a $G$ protein-coupled receptor (GPCR) that signals through the Gq pathway, in turn activating PI-3 kinase pathway [48]. FKN is expressed in neurons and peripheral endothelial and its receptor is produced by myeloid cells (including microglia), T cells, and natural killer cells $[49,50]$. FKN is a type I transmembrane protein with an $\mathrm{N}$-terminal chemokine domain attached to a long, highly glycosylated mucin-like stalk with a short membrane-spanning domain and intracellular domain. FKN can be cleaved by a disintegrin and metalloprotease (ADAM) 10, ADAM 17, and cathepsin $S$ to generate a soluble fragment [2-4] (Fig. 1). Both the membrane-bound and soluble forms of FKN are capable of signaling through CX3CR1, although there may be differences in affinity and biological activity between these two ligands [1].

In the periphery, membrane-bound FKN can promote adhesion of monocytes to endothelial cells, and the soluble ligand can cause chemotaxis of monocytes, T cells, and natural killer cells [51, 52]. Genetic ablation of FKN causes reduced monocyte survival and reduced ability of CX3CR $1^{+}$macrophages to sense the gut lumen [53]. Expression of the chemokine domain of FKN was sufficient to rescue survival of certain populations of monocytes
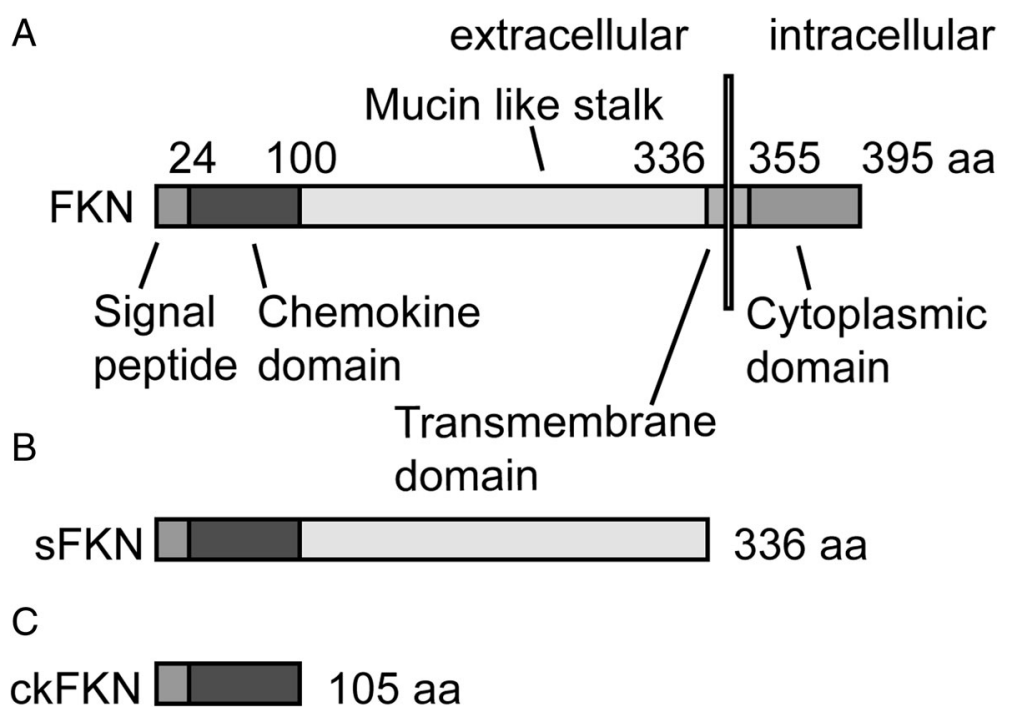

Fig. 1 Diagrammatic representation of FKN and proteolytic cleavage fragments. a Full-length FKN variant is membrane-associated protein with a short cytoplasmic domain, a single transmembrane domain, and an extracellular mucin-like stalk and chemokine domain. b Soluble FKN (sFKN). Putative ADAM10/17 cleavage variant, generating a soluble FKN that includes the mucin-like stalk. c A theoretical fragment of FKN containing only the chemokine domain. This peptide is typically used for recombinant peptide studies 
and to rescue the ability of $\mathrm{CX} 3 \mathrm{CR} 1^{+}$macrophages to form transepithelial dendrites. In the CNS, fractalkine is predominantly expressed by neurons, and CX3CR 1 is found only on microglia $[1,12,50]$.

Single-nucleotide polymorphisms (SNPs) of CX3CR1 have been implicated as risk factors in several diseases. There is a correlation between these two SNPs and age-related macular degeneration and coronary artery disease [54-57]. These SNPs increase risk for age-related macular degeneration but reduce the risk of coronary artery disease. It was also observed that HIV-positive patients homozygous for both SNPs more rapidly converted to AIDs [58]. These SNPs may impact receptor function or receptor expression on monocytes. There is evidence that these SNPs reduce affinity of the receptor for FKN and may reduce surface receptor expression on monocytes [55]. Genetic knockout of both the receptor and the ligand have shed light on the role of FKN signaling in development, homeostasis, and disease.

\section{CX3CR1 knock out models and neurodegenerative diseases}

Generation of a reporter mouse, replacing endogenous $\mathrm{Cx} 3 \mathrm{cr} 1$ with a green fluorescent protein (GFP) reporter under control of the $C x 3 c r 1$ promoter, demonstrated that CX3CR1 expression is restricted to microglia in the CNS $[12,59]$. This reporter line has been used extensively to investigate the impacts of disrupting FKN signaling from the developing to the aged brain. In development, CX3CR1 deficient mice were observed to have delayed synaptic pruning. Microglial number was transiently reduced in $\mathrm{C} x 3 \mathrm{cr} 1$ -/- mice compared to wild-type controls while the number of dendritic spines was increased. This indicates that CX3CR1 deficiency may delay maturation of synapses by delaying engulfment during development [60]. In the adult brain, CX3CR1 has been identified as necessary for layer $\mathrm{V}$ cortical neuron survival [61]. These findings implicated FKN signaling in normal brain development and homeostasis but ablation of CX3CR1 also affects cognition.

Disruption of FKN signaling has deleterious effects on both neurogenesis and cognition. Cx3cr1-/- mice were found to have a significant reduction in neurogenesis, which could be reversed by IL-1 receptor antagonist administration [62]. When behaviorally assessed, these mice were found to have motor learning impairments, spatial recall impairments, and fear-associated recall impairments. These cognitive impairments were associated with reduced synaptic plasticity. Antagonism of IL-1 $\beta$ signaling successfully reversed hippocampal-dependent learning but not motor learning [63].

Disruption of FKN signaling has also been studied in the context of neurodegenerative disorders. In a seminal paper, Cardona et al. [12] described the impact of
CX3CR1 knock out in several models of neurodegeneration. Broadly, they found that microglia lacking CX3CR1 are cytotoxic in models of systemic inflammation, amyotrophic lateral sclerosis (ALS), and Parkinson's disease (PD). Mice lacking CX3CR1 were more susceptible to neuron loss upon systemic injection of LPS. Furthermore, adoptive transfer of $\mathrm{Cx} 3 \mathrm{cr} 1-/-$ microglia from LPS-challenged mice into wild-type mice also produced neurotoxicity in the area of the injection site. Interestingly, microglia lacking CX3CR1 did not migrate away from the injection site whereas microglia with intact CX3CR1 signaling migrated from the injection site. Inhibition of IL- $1 \beta$ signaling blocked the neurotoxic effects of and restored the migratory capacity of $\mathrm{C} \times 3 \mathrm{cr} 1-/-$ microglia. Similarly, in the SOD ${ }^{\mathrm{G} 93 \mathrm{~A}}$ mouse model of ALS, disruption of FKN signaling caused greater neuron loss, reduced hindlimb strength, and shortened lifespan. In a toxic model of PD, loss of FKN signaling by knocking out either the receptor or the ligand resulted in significantly greater neurotoxicity [12].

In models of ischemia, the role of FKN has been less straightforward. It has been shown that genetic ablation of either CX3CR1 or CX3CL1 reduced infarct size in ischemic models [8, 10, 64, 65]. However, administration of exogenous CX3CL1 into wild-type rats subjected to middle cerebral artery occlusion was found to be beneficial, reducing infarct volume and improving behavioral outcomes [64]. These effects were not seen when exogenous CX3CL1 was administered to Cx3cl1-/- mice, in which exogenous CX3CL1 ablated the protective effects observed in untreated $C \times 3 c l 1-/-$ mice. Cipriani et al. [64] attributed these seemingly contradictory results to differential response of wild-type primary microglia to exogenous CX3CL1 in vitro. They observed no reduction in TNF $\alpha$ secreted from stimulated wild-type microglia after treatment with CX3CL1 whereas microglia isolated from Cx3cl1-/- mice did reduce TNF $\alpha$ secretion after treatment with CX3CL1.

FKN signaling has been studied in spinal cord and brain injury models. In a mild traumatic brain injury model, FKN signaling has been shown to have a temporally dependent action. In the first 15 days after the injury, Cx3cr1-/- mice exhibit significantly less impairment as well as reduce pro-inflammatory markers. However, 30 days after injury $\mathrm{C} \times 3 \mathrm{cr} 1-/-$ mice have significantly greater memory impairment on the Morris water maze as well as significantly elevated pro-inflammatory markers compared to wild-type controls [66]. Similar results as those found in stroke models have been observed in a spinal cord injury model, that is, disrupting FKN signaling confers neuroprotection and improves behavioral outcomes [67]. However, these effects were largely attributed to a blunting of the inflammatory phenotype acquired by infiltrating monocytes. 


\section{CX3CR1CX3CL1 in AD}

The effects of disrupting FKN agonism has also been studied in AD models. FKN expression in both the hippocampus and cortex is reduced in AD brain compared with non-demented controls [13], suggesting a dysregulation of this pathway in AD. Several studies have shed light on the role of FKN signaling in AD. It has been shown in two models of amyloid deposition that disrupting FKN signaling by knocking out $C x 3 \mathrm{cr} 1$ is beneficial. In both models, a reduction in amyloid plaques was observed accompanied by an increase in microglial phagocytosis [7, 68]. Conversely, it has been observed that FKN signaling is beneficial in tau pathology. In the hTau mouse model of tauopathy, it was observed that disrupting FKN signaling worsened pathology and accelerated insoluble tau deposition. These increases in pathology were accompanied by an impairment in spatial working memory [11]. A further study showed deficits in Morris water maze and, importantly, that CD45 immunoreactivity precedes tau hyperphosphorylation in this model. In an adoptive transfer model, wild-type mice receiving microglia from hTau Cx3cr1-/- mice showed increased AT8 immunoreactivity that could be blocked with IL-1Ra [69]. Additional studies in amyloid models have also observed a worsening of tau pathology in the absence of FKN signaling $[13,16]$. Thus, FKN may have complex interactions with the hallmark pathologies of AD and may be neuroprotective or neurotoxic at different timepoints in disease progression.

Interestingly, recent reports implicate direct interaction between CX3CR1 and tau. Bolos et al. (2017) [70] demonstrated that tau can directly bind to CX3CR1 and competes with FKN. This may result in a disruption of the neuronal/glial communication and thus uncoupling of microglial activation. Bolos et al. (2017) [70] also report a significant increase in immunohistochemical staining for FKN in the AD brain, however, more recently, they reported a concomitant reduction in soluble FKN in the cerebrospinal fluid of AD patients [71] compared to non-demented age-matched controls. Suggesting that there may be a reduction in FKN processing to the soluble form. The soluble form of FKN has been suggested to be more anti-inflammatory and neuroprotective than the membrane bound form [72]. As tau can directly stimulate expression of pro-inflammatory cytokines in primary microglia [73], these data indicate both a reduction in anti-inflammatory signaling, by reduced cleavage of FKN, synergizes with the pro-inflammatory stimulus of extracellular tau to contribute to neuroinflammation in AD.

\section{CX3CL1 gain of function studies}

A series of studies have examined the effects of over expression of FKN in different neurological disorders. Studies increasing FKN in PD have found that increased
CX3CR1 agonism is beneficial. Bachstetter et al. [74] described the protective effects of a soluble FKN ligand in the 6-hydroxydopamine model of PD. In this model, increased FKN agonism resulted in reduced microglial activation, reduced lesion size, and protection of dopaminergic neurons in the substantia nigra. Similar results were observed when $\mathrm{Cx} 3 \mathrm{cl} 1-/-$ mice were lesioned with MPTP and injected with adeno-associated virus (AAV) over-expressing FKN. Animals injected with FKN showed significant improvement compared to AAV over-expressing GFP-injected mice [72]. Finally, it was shown that FKN was also able to halt neurodegeneration in a viral model of $\alpha$-synuclein over expression [75]. These data suggest an increase in CX3CR1 agonism is a therapeutic target for the treatment of neurodegeneration in PD.

Examining the effects of FKN over expression on tauopathy has yielded encouraging results. Over expression of a soluble FKN (sFKN; predicted to be the ADAM10/ 17 cleavage product, Fig. 1) via AAV in the rTg4510 mouse model of tauopathy reduced both soluble and insoluble phospho-tau pathology, ameliorated neuron loss, and reduced microglial activation. This is one of the first therapeutic interventions that were able to reduce brain atrophy in this model. Interestingly, from the $C \times 3 \mathrm{cr} 1-/-$ studies described above, one may predict that the FKN over expression may worsen amyloid pathology [7, 9, 68]. However, when sFKN was over expressed in the APP/PS1 model of amyloid deposition, there was not a significant impact on amyloid pathology [76]. This highlights that CX3CR1 agonism may be a potential target for immunomodulation, with beneficial effects on tauopathy and no observed detrimental effects on amyloid deposition.

\section{Fractalkine signaling: does the ligand matter?}

There is some evidence that different fragments of the FKN ligand may have different functional outcomes. Fractalkine signaling has been implicated in neuropathic pain in spinal injury models [77-79]. In these studies, neuropathic pain in injury models was alleviated by antibody antagonization of CX3CR1, and in non-injured rats neuropathic pain was induced by activation of CX3CR1 with intrathecal injections of exogenous fractalkine peptide comprising just the chemokine domain. Furthermore, Clark and Malcangio [15] show that infusion of this chemokine peptide of FKN (ckFKN, Fig. 1) elicits mechanical allodynia, while infusion of sFKN (which contains the full mucin-like stalk, Fig. 1) does not. They also demonstrate a difference in calcium mobilization upon binding between these two fragments. Interestingly, it has been identified that cathepsin $S$ is necessary for the production of pain-inducing FKN in a spinal injury model [2, 77]. In silico analysis of substrate 
preference of cathepsin $\mathrm{S}$ indicates membrane-bound FKN as a potential substrate [77, 80-82] and a recent study published that cathepsin $\mathrm{S}$ cleaves membrane bound FKN to generate a soluble fragment that migrates at a lower apparent molecular weight than the ADAM10/17 cleavage product [83]. These data suggest that removal of the mucin-like stalk (either partially or in whole) may alter the microglial response to FKN, which can elicit different effects and/or microglial phenotypes depending on the identity of the soluble ligand.

Differences in signaling also appear to occur in neurodegenerative diseases. In Parkinson's disease, studies have shown that a soluble FKN is necessary for neuroprotection in both a MPTP and an $\alpha$-synuclein over expression model, whereas a membrane bound form of FKN had no protective effects $[72,75]$. These data indicate that neuroprotective signaling in the CNS by FKN is dependent on its cleavage. The results in Alzheimer's disease are not as clear. In order to determine the relative contributions of soluble versus membrane-associated FKN to AD pathology, a transgenic mouse that only expresses the chemokine domain of FKN, termed SolTg or CX3CL $1^{105 \Delta}$, was developed and crossed with AD mouse models. In a cross of this ckFKN-expressing mouse with an APP/ PS1; Cx3cl1-/- mouse, Lee et al. [16] observed that ckKFN failed to have an impact on either amyloid or tau pathology as compared to APP/PS1; Cx3cl1-/control mice. They argued that it is therefore the membrane-bound variant of FKN, and not a soluble ligand, that impacts amyloid pathology. In a more recent report, Bemiller et al. [14] observed an increased susceptibility to LPS-induced tauopathy and microglial activation in the mice expressing only ckFKN. Furthermore, they show that hTau mice expressing ckFKN (hTau/CX3CL1 ${ }^{105 \Delta}$ ) had similar phospho-tau pathology and cognitive deficits as hTau; Cx3cl1-/mice, both of which had significantly greater phospho-tau pathology and cognitive deficits than hTau mice expressing endogenous FKN. The authors observed a reduction in CX3CR1 receptor expression on microglia in ckFKN expressing mice as compared to either non-transgenic or $C x 3 c l 1-/-$ mice, perhaps explaining the reduced biological activity of ckFKN as compared to endogenous FKN in this model. Contrary to these data, Nash et al. [76] observed neuroprotective effects using a different soluble FKN, the putative ADAM10/17 cleavage product, which contains the mucin-like stalk and the chemokine domain. They observed reductions in brain atrophy, tau pathology, and neurodegeneration in the rTg4510 tau model [76]. These data may indicate that the form of the soluble fragment (with or without the mucin stalk) affects how the chemokine signals in these neurodegenerative models and that proteolytic cleavage could be a mechanism for regulation of fractalkine activity in vivo. More research is needed to determine if there are differential effects of these soluble FKN variants and how this could regulate neuroinflammation.

\section{Conclusion}

Recent discovery of innate immunity genes conferring increased risk of $\mathrm{AD}$ has sparked greater interest in the role of inflammation in AD. As our understanding of the role inflammation plays in $\mathrm{AD}$ increases, it becomes progressively clear that immunomodulators are a more attractive therapeutic approach rather than broadly suppressing immune activity. One such target is fractalkine, which shares a one-to-one relationship with its receptor. In the CNS, fractalkine is expressed by neurons and signals its receptor by microglia, thus allowing neurons to directly influence neuroinflammation. Fractalkine's involvement in neurodegeneration has been relatively controversial, with disruption of fractalkine signaling being beneficial in some disease states (amyloid pathology and stroke) and yet detrimental in other neurodegenerative diseases (PD, ALS, and tauopathies). Increasing FKN agonism has been shown to be neuroprotective in both AD and PD models; however, there is some controversy in the field regarding which form of FKN mediates the observed neuroprotection. More research is needed to fully understand the therapeutic potential of FKN in $\mathrm{AD}$, with special attention to ligand processing and how this regulates microglial activation.

\section{Abbreviations \\ ADAM: A disintegrin and metalloprotease; AAV: Adeno-associated virus; AD: Alzheimer's disease; A $\beta$ : Amyloid- $\beta$; APP: Amyloid precursor protein; ALS: Amyotrophic lateral sclerosis; CNS: Central nervous system; CX3CL1; FKN: Fractalkine; GPCR: G protein-coupled receptor; GFP: Green fluorescent protein; IL: Interleukin; LPS: Lipopolysaccharide; LOAD: Late onset Alzheimer's disease; TSPO: Microglial translocator protein; MAPT: Microtubule associated protein tau; NFTs: Neurofibrillary tangles; PD: Parkinson's disease; SNPS: Single-nucleotide polymorphisms; TREM2: Triggering receptor expressed on myeloid cells 2; TNFa: Tumor necrosis factor-a}

\section{Acknowledgements}

Not applicable.

Funding

Not applicable

Availability of data and materials

Not applicable.

Authors' contributions

DJF wrote the initial draft. Modifications suggested by KRN were applied by DJF and KRN. All authors read and approved the final version.

Ethics approval

Not applicable.

Consent for publication

Not applicable. 


\section{Competing interests}

The authors declare that they have no competing interests.

\section{Publisher's Note}

Springer Nature remains neutral with regard to jurisdictional claims in published maps and institutional affiliations.

Received: 2 November 2018 Accepted: 23 January 2019

Published online: 11 February 2019

\section{References}

1. Harrison JK, Jiang Y, Chen SZ, Xia YY, Maciejewski D, McNamara RK, et al. Role for neuronally derived fractalkine in mediating interactions between neurons and CX3CR1-expressing microglia. Proc Natl Acad Sci U S A. 1998; 95(18):10896-901.

2. Clark AK, Yip PK, Malcangio M. The liberation of fractalkine in the dorsal horn requires microglial cathepsin S. J Neurosci. 2009;29(21):6945-54.

3. Garton KJ, Gough PJ, Blobel CP, Murphy G, Greaves DR, Dempsey PJ, et al. Tumor necrosis factor-alpha-converting enzyme (ADAM17) mediates the cleavage and shedding of fractalkine (CX3CL1). J Biol Chem. 2001;276(41): 37993-8001.

4. Hundhausen C, Misztela D, Berkhout TA, Broadway N, Saftig P, Reiss K, et al. The disintegrin-like metalloproteinase ADAM10 is involved in constitutive cleavage of CX3CL1 (fractalkine) and regulates CX3CL1-mediated cell-cell adhesion. Blood. 2003;102(4):1186-95.

5. Zujovic V, Benavides J, Vige X, Carter C, Taupin V. Fractalkine modulates TNF-alpha secretion and neurotoxicity induced by microglial activation. Glia. 2000;29(4):305-15.

6. Zujovic V, Schussler $N$, Jourdain D, Duverger D, Taupin V. In vivo neutralization of endogenous brain fractalkine increases hippocampal TNF and 8-isoprostane production induced by intracerebroventricular injection of LPS. J Neuroimmunol. 2001;115:135-43.

7. Lee S, Varvel NH, Konerth ME, Xu G, Cardona AE, Ransohoff RM, et al. CX3CR1 deficiency alters microglial activation and reduces beta-amyloid deposition in two Alzheimer's disease mouse models. Am J Pathol. 2010; 177(5):2549-62.

8. Soriano SG, Amaravadi LS, Wang YF, Zhou H, Yu GX, Tonra JR, et al. Mice deficitin in fractalkine are less susceptible to cerebral ischemia-reperfusion injury. J Neuroimmunology. 2002;125:59-65.

9. Fuhrmann $M$, Bittner $T$, Jung $C K$, Burgold $S$, Page RM, Mitteregger $G$, et al. Microglial Cx3cr1 knockout prevents neuron loss in a mouse model of Alzheimer's disease. Nat Neurosci. 2010;13(4):411-3.

10. Dénes Á, Ferenczi S, Halász J, Környei Z, Kovács KJ. Role of CX3CR1 (fractalkine receptor) in brain damage and inflammation induced by focal cerebral ischemia in mouse. J Cereb Blood Flow Metab. 2008:28(10):1707-21.

11. Bhaskar K, Konerth M, Kokiko-Cochran ON, Cardona A, Ransohoff RM, Lamb BT. Regulation of tau pathology by the microglial fractalkine receptor. Neuron. 2010;68(1):19-31

12. Cardona AE, Pioro EP, Sasse ME, Kostenko V, Cardona SM, Dijkstra IM, et al. Control of microglial neurotoxicity by the fractalkine receptor. Nat Neurosci. 2006;9(7):917-24

13. Cho SH, Sun B, Zhou Y, Kauppinen TM, Halabisky B, Wes P, et al. CX3CR1 protein signaling modulates microglial activation and protects against plaque-independent cognitive deficits in a mouse model of Alzheimer disease. J Biol Chem. 2011;286(37):32713-22.

14. Bemiller SM, Maphis NM, Formica SV, Wilson GN, Miller CM, Xu G, et al. Genetically enhancing the expression of chemokine domain of $\mathrm{CX} 3 \mathrm{CL} 1$ fails to prevent tau pathology in mouse models of tauopathy. $J$ Neuroinflammation. 2018;15(1):278

15. Clark AK, Malcangio M. Microglial signalling mechanisms: cathepsin S and fractalkine. Exp Neurol. 2012;234(2):283-92

16. Lee $S, X u$ G, Jay TR, Bhatta S, Kim KW, Jung S, et al. Opposing effects of membrane-anchored CX3CL1 on amyloid and tau pathologies via the p38 MAPK pathway. J Neurosci. 2014;34(37):12538-46.

17. Quefurth HW, LaFerla FM. Alzheimer's disease. N Engl J Med. 2010;362(4): 329-44

18. Akiyama H, Barger S, Barnum S, Bradt B, Bauer J, Cole GM, et al Inflammation and Alzheimer's disease. Neurobiol Aging. 2000;21(3):383-421.

19. Selkoe DJ. Amyloid beta-protein and the genetics of Alzheimer's disease. J Biol Chem. 1996;271(31):18295-8.
20. Gallardo G, Holtzman DM. Antibody therapeutics targeting abeta and tau. Cold Spring Harb Perspect Med. 2017;7:10.

21. Morgan D, Gordon MN, Tan J, Wilcock D, Rojiani AM. Dynamic complexity of the microglial activation response in transgenic models of amyloid deposition: implications for Alzheimer therapeutics. J Neuropathol Exp Neurol. 2005:64(9):743-53.

22. Edison P, Donat CK, Sastre M. In vivo imaging of glial activation in Alzheimer's disease. Front Neurol. 2018;9:625.

23. Fan Z, Brooks DJ, Okello A, Edison P. An early and late peak in microglial activation in Alzheimer's disease trajectory. Brain. 2017;140(3):792-803.

24. McGeer PL, Rogers J, McGeer EG. Inflammation, anti-inflammatory agents and Alzheimer disease: the last 12 years. J Alzheimers Dis. 2006;9:271-6.

25. Aisen PS, Davis KL, Berg JD, Schafer K, Campbell K, Thomas RG, et al. A randomized controlled trial of prednisone in Alzheimer's disease. Alzheimers Disease Cooperative Study. Neurology. 2000:54(3):588-93.

26. Thal LJ, Ferris SH, Kirby L, Block GA, Lines CR, Yuen E, et al. A randomized, double-blind, study of rofecoxib in patients with mild cognitive impairment. Neuropsychopharmacology. 2005;30(6):1204-15.

27. Herber DL, Mercer M, Roth LM, Symmonds K, Maloney J, Wilson N, et al. Microglial activation is required for Abeta clearance after intracranial injection of lipopolysaccharide in APP transgenic mice. J Neurolmmune Pharmacol. 2007;2(2):222-31.

28. Shaftel SS, Kyrkanides S, Olschowka JA, Miller JN, Johnson RE, O'Banion MK Sustained hippocampal IL-1 beta overexpression mediates chronic neuroinflammation and ameliorates Alzheimer plaque pathology. J Clin Invest. 2007;117(6):1595-604

29. Lee DC, Rizer J, Selenica ML, Reid P, Kraft C, Johnson A, et al. LPS- induced inflammation exacerbates phospho-tau pathology in rTg4510 mice. J Neuroinflammation. 2010;7(56):56.

30. Hollingworth P, Harold D, Sims R, Gerrish A, Lambert JC, Carrasquillo MM, et al. Common variants at ABCA7, MS4A6AMMS4A4E, EPHA1, CD33 and CD2AP are associated with Alzheimer's disease. Nat Genet. 2011:43(5):429-35.

31. Naj AC, Jun G, Beecham GW, Wang LS, Vardarajan BN, Buros J, et al. Common variants at MS4A4/MS4A6E, CD2AP, CD33 and EPHA1 are associated with lateonset Alzheimer's disease. Nat Genet. 2011;43(5):436-41.

32. Lambert JC, Heath S, Even G, Campion D, Sleegers $K$, Hiltunen $M$, et al. Genome-wide association study identifies variants at CLU and CR1 associated with Alzheimer's disease. Nat Genet. 2009:41(10):1094-9.

33. Jonsson T, Stefansson H, Steinberg S, Jonsdottir I, Jonsson PV, Snaedal J, et al. Variant of TREM2 associated with the risk of Alzheimer's disease. N Engl J Med. 2013;368(2):107-16.

34. Zhang B, Gaiteri C, Bodea LG, Wang Z, McElwee J, Podtelezhnikov AA, et al. Integrated systems approach identifies genetic nodes and networks in lateonset Alzheimer's disease. Cell. 2013;153(3):707-20.

35. Ardura-Fabregat A, Boddeke E, Boza-Serrano A, Brioschi S, Castro-Gomez S, Ceyzeriat $\mathrm{K}$, et al. Targeting neuroinflammation to treat Alzheimer's disease. CNS Drugs. 2017;31(12):1057-82

36. Hopperton KE, Mohammad D, Trepanier MO, Giuliano V, Bazinet RP. Markers of microglia in post-mortem brain samples from patients with Alzheimer's disease: a systematic review. Mol Psychiatry. 2018;23(2):177-98.

37. Culpan D, MacGowan SH, Ford JM, Nicoll JA, Griffin WS, Dewar D, et al. Tumour necrosis factor-alpha gene polymorphisms and Alzheimer's disease. Neurosci Lett. 2003:350(1):61-5.

38. Nicoll JA, Mrak RE, Graham DI, Stewart J, Wilcock G, MacGowan S, et al. Association of interleukin-1 gene polymorphisms with Alzheimer's disease. Ann Neurol. 2000;47(3):365-8.

39. Dansokho C, Heneka MT. Neuroinflammatory responses in Alzheimer's disease. J Neural Transm (Vienna). 2018;125(5):771-9.

40. Villegas-Llerena C, Phillips A, Garcia-Reitboeck P, Hardy J, Pocock JM. Microglial genes regulating neuroinflammation in the progression of Alzheimer's disease. Curr Opin Neurobiol. 2016;36:74-81.

41. Sims R, van der Lee SJ, Naj AC, Bellenguez C, Badarinarayan N, Jakobsdottir $J$, et al. Rare coding variants in PLCG2, ABI3, and TREM2 implicate microglial-mediated innate immunity in Alzheimer's disease. Nat Genet. 2017:49(9):1373-84.

42. Guo L, LaDu MJ, Van Eldik LJ. A dual role for apolipoprotein e in neuroinflammation: anti- and pro-inflammatory activity. J Mol Neurosci. 2004:23(3):205-12

43. Hickman SE, Allison EK, El Khoury J. Microglial dysfunction and defective beta-amyloid clearance pathways in aging Alzheimer's disease mice. J Neurosci. 2008;28(33):8354-60. 
44. Lucin KM, O'Brien CE, Bieri G, Czirr E, Mosher Kl, Abbey RJ, et al. Microglial Beclin 1 regulates retromer trafficking and phagocytosis and is impaired in Alzheimer's disease. Neuron. 2013;79(5):873-86.

45. Parkhurst CN, Yang G, Ninan I, Savas JN, Yates JR 3rd, Lafaille JJ, et al. Microglia promote learning-dependent synapse formation through brainderived neurotrophic factor. Cell. 2013;155(7):1596-609.

46. Bazan JF, Bacon KB, Hardiman G, Wang W, Soo K, Rossi D, et al. A new class of membrane-bound chemokine with a CX3C motif. Nature. 1997;385(6617): 640-4.

47. Pan Y, Lloyd C, Zhou H, Dolich S, Deeds J, Gonzalo JA, et al. Neurotactin, a membrane-anchored chemokine upregulated in brain inflammation. Nature. 1997;387(6633):611-7.

48. Lyons A, Lynch AM, Downer EJ, Hanley R, O'Sullivan JB, Smith A, et al. Fractalkine-induced activation of the phosphatidylinositol-3 kinase pathway attentuates microglial activation in vivo and in vitro. J Neurochem. 2009; 110(5):1547-56.

49. Garcia JA, Pino PA, Mizutani M, Cardona SM, Charo IF, Ransohoff RM, et al. Regulation of adaptive immunity by the fractalkine receptor during autoimmune inflammation. J Immunol. 2013;191(3):1063-72.

50. Hatori K, Nagai A, Heisel R, Ryu JK, Kim SU. Fractalkine and fractalkine receptors in human neurons and glial cells. J Neurosci Res. 2002;69(3):418-26.

51. Imai T, Hieshima K, Haskell CA, Baba M, Nagira M, Nishimura M, et al. Identification and molecular characterization of fractalkine receptor CX3CR1, which mediates both leukocyte migration and adhesion. Cell. 1997;91:521-30.

52. Ostuni MA, Guellec J, Hermand P, Durand P, Combadiere C, Pincet F, et al. CX3CL1, a chemokine finely tuned to adhesion: critical roles of the stalk glycosylation and the membrane domain. Biol Open. 2014;3(12):1173-82.

53. Kim KW, Vallon-Eberhard A, Zigmond E, Farache J, Shezen E, Shakhar G, et al. In vivo structure/function and expression analysis of the $\mathrm{CX} 3 \mathrm{C}$ chemokine fractalkine. Blood. 2011;118(22):e156-67.

54. Chan CC, Tuo J, Bojanowski CM, Csaky KG, Green WR. Detection of CX3CR1 single nucleotide polymorphism and expression on archived eyes with agerelated macular degeneration. Histol Histopathol. 2005;20(3):857-63.

55. Moatti D, Faure S, Fumeron F, Amara MEW, Seknadji P, McDermott DH, et al. Polymorphism in the fractalkine receptor CX3CR1 as a genetic risk factor for coronary artery disease. Blood. 2001;97(7):1925-8.

56. Nassar BA, Nanji AA, Ransom TP, Rockwood K, Kirkland SA, Macpherson K, et al. Role of the fractalkine receptor CX3CR1 polymorphisms V249I and T280M as risk factors for early-onset coronary artery disease in patients with no classic risk factors. Scand J Clin Lab Invest. 2008;68(4):286-91.

57. Tuo J, Smith BC, Bojanowski CM, Meleth AD, Gery I, Csaky KG, et al. The involvement of sequence variation and expression of CX3CR1 in the pathogenesis of age-related macular degeneration. FASEB J. 2004;18(11):1297-9.

58. Faure $\mathrm{S}$, Meyer L, Costagliola D, Vaneensberghe C, Genin E, Autran B, et al. Rapid progression to AIDS in HIV+ individuals with a structural variant of the chemokine receptor CX3CR1. Science. 2000;287(5461):2274-7.

59. Jung S, Aliberti J, Graemmel P, Sunshine MJ, Kreutzberg GW, Sher A, et al. Analysis of fractalkine receptor CX3CR1 function by targeted deletion and green fluorescent protein reporter gene insertion. Mol Cell Biol. 2000;20(11): 4106-14.

60. Paolicelli RC, Bolasco G, Pagani F, Maggi L, Scianni M, Panzanelli P, et al. Synaptic pruning by microglia is necessary for normal brain development. Science. 2011;333(6048):1456-8.

61. Ueno M, Fujita Y, Tanaka T, Nakamura Y, Kikuta J, Ishii M, et al. Layer V cortical neurons require microglial support for survival during postnatal development. Nat Neurosci. 2013;16(5):543-51.

62. Bachstetter AD, Morganti JM, Jernberg J, Schlunk A, Mitchell SH, Brewster KW, et al. Fractalkine and CX 3 CR1 regulate hippocampal neurogenesis in adult and aged rats. Neurobiol Aging. 2011;32(11):2030-44.

63. Rogers JT, Morganti JM, Bachstetter AD, Hudson CE, Peters MM, Grimmig BA, et al. CX3CR1 deficiency leads to impairment of hippocampal cognitive function and synaptic plasticity. J Neurosci. 2011;31(45):16241-50.

64. Cipriani R, Villa P, Chece G, Lauro C, Paladini A, Micotti E, et al. CX3CL1 is neuroprotective in permanent focal cerebral ischemia in rodents. J Neurosci. 2011;31(45):16327-35.

65. Fumagalli S, Perego C, Ortolano F, De Simoni MG. CX3CR1 deficiency induces an early protective inflammatory environment in ischemic mice. Glia. 2013;61(6):827-42

66. Febinger HY, Thomasy HE, Pavlova MN, Ringgold KM, Barf PR, George AM, et al. Time-dependent effects of CX3CR1 in a mouse model of mild traumatic brain injury. J Neuroinflammation. 2015;12:154.
67. Donnelly DJ, Longbrake EE, Shawler TM, Kigerl KA, Lai W, Tovar CA, et al Deficient CX3CR1 signaling promotes recovery after mouse spinal cord injury by limiting the recruitment and activation of Ly6Clo/iNOS+ macrophages. J Neurosci. 2011;31(27):9910-22.

68. Liu Z, Condello C, Schain A, Harb R, Grutzendler J. CX3CR1 in microglia regulates brain amyloid deposition through selective protofibrillar amyloidbeta phagocytosis. J Neurosci. 2010;30(50):17091-101.

69. Maphis N, Xu G, Kokiko-Cochran ON, Jiang S, Cardona A, Ransohoff RM, et al. Reactive microglia drive tau pathology and contribute to the spreading of pathological tau in the brain. Brain. 2015;138(Pt 6):1738-55.

70. Bolos M, Llorens-Martin M, Perea JR, Jurado-Arjona J, Rabano A, Hernandez $F$, et al. Absence of CX3CR1 impairs the internalization of tau by microglia. Mol Neurodegener. 2017;12(1):59.

71. Perea JR, Lleo A, Alcolea D, Fortea J, Avila J, Bolos M. Decreased CX3CL1 levels in the cerebrospinal fluid of patients with Alzheimer's disease. Front Neurosci. 2018;12:609.

72. Morganti JM, Nash KR, Grimmig BA, Ranjit S, Small B, Bickford PC, et al. The soluble isoform of CX3CL1 is necessary for neuroprotection in a mouse model of Parkinson's disease. J Neurosci. 2012;32(42):14592-601.

73. Perea JR, Avila J, Bolos M. Dephosphorylated rather than hyperphosphorylated tau triggers a pro-inflammatory profile in microglia through the p38 MAPK pathway. Exp Neurol. 2018:310:14-21.

74. Pabon MM, Bachstetter AD, Hudson CE, Gemma C, Bickford PC. CX3CL1 reduces neurotoxicity and microglial activation in a rat model of Parkinson's disease. J Neuroinflammation. 2011:8:9.

75. Nash KR, Moran P, Finneran DJ, Hudson C, Robinson J, Morgan D, et al. Fractalkine over expression suppresses alpha-synuclein-mediated neurodegeneration. Mol Ther. 2015;23(1):17-23.

76. Nash KR, Lee DC, Hunt JB Jr, Morganti JM, Selenica ML, Moran P, et al. Fractalkine overexpression suppresses tau pathology in a mouse model of tauopathy. Neurobiol Aging. 2013;34(6):1540-8.

77. Clark AK, Yip PK, Grist J, Gentry C, Staniland AA, Marchand F, et al. Inhibition of spinal microglial cathepsin $S$ for the reversal of neuropathic pain. Proc Natl Acad Sci U S A. 2007;104(25):10655-60.

78. Sun JL, Xiao C, Lu B, Zhang J, Yuan XZ, Chen W, et al. CX3CL1/CX3CR1 regulates nerve injury-induced pain hypersensitivity through the ERK5 signaling pathway. J Neurosci Res. 2013;91(4):545-53.

79. Milligan ED, Zapata V, Chacur M, Schoeniger D, Biedenkapp J, O'Connor KA, et al. Evidence that exogenous and endogenous fractalkine can induce spinal nociceptive facilitation in rats. Eur J Neurosci. 2004;20(9):2294-302.

80. Biniossek ML, Nagler DK, Becker-Pauly C, Schilling O. Proteomic identification of protease cleavage sites characterizes prime and non-prime specificity of cysteine cathepsins B, L, and S. J Proteome Res. 2011;10(12): 5363-73.

81. Jones BA, Riegsecker S, Rahman A, Beamer M, Aboualaiwi W, Khuder SA, et al. Role of ADAM-17, p38 MAPK, cathepsins, and the proteasome pathway in the synthesis and shedding of fractalkine/CX(3) CL1 in rheumatoid arthritis. Arthritis Rheum. 2013:65(11):2814-25.

82. Ruckrich T, Brandenburg J, Cansier A, Muller M, Stevanovic S, Schilling K, et al. Specificity of human cathepsin $\mathrm{S}$ determined by processing of peptide substrates and MHC class II-associated invariant chain. Biol Chem. 2006; 387(10-11):1503-11.

83. Fonovic UP, Jevnikar Z, Kos J. Cathepsin S generates soluble CX3CL1 (fractalkine) in vascular smooth muscle cells. Biol Chem. 2013;394(10):1349-52.

Ready to submit your research? Choose BMC and benefit from:

- fast, convenient online submission

- thorough peer review by experienced researchers in your field

- rapid publication on acceptance

- support for research data, including large and complex data types

- gold Open Access which fosters wider collaboration and increased citations

- maximum visibility for your research: over $100 \mathrm{M}$ website views per year

At $\mathrm{BMC}$, research is always in progress.

Learn more biomedcentral.com/submissions 